\title{
ERROS DE PRESCRIÇÃO E DISPENSAÇÃO DE ANTIMICROBIANOS EM UMA FARMÁCIA COMUNITÁRIA
}

\author{
PRESCRIPTION AND DISPENSING ERRORS OF ANTIMICROBIALS IN A \\ COMUNITY PHARMACY
}

Isadora Oliveira e Pereira, Lucas Brasileiro Lemos, Paulo Henrique Ribeiro Fernandes Almeida, Gisele da Silveira Lemos

Universidade Estadual do Sudoeste da Bahia - UESB

\begin{abstract}
It is understood as a prescription the legal document elaborated by healtchcare professionals, subjected to control legislation and sanitary vigilance. It constitutes an important comunication tool between professionals and the patient, that in the presence of irregularities may cause the incorrect use of medications. The objective of this study was to analyse prescription and dispensing antimicrobial errors, in a way to verify the frequency and the associated factors, according to the legislations in force. It consisted of a transverse, analytical and descriptive study, executed starting at the documental analysis of 404 topic and sistemic antimicrobial prescriptions listed in the RDC no20/2011, made available by the matrix of a chain of pharmacies, referent to the month of may, 2018, using a pre-established form elaborated with basis in the prescription, use and administration safety protocol. The results showed errors related to the patients' name in 33,4\% of prescriptions, the prescriptor's stamp was absent in $8,2 \%$ and the pharmaceutical form issue contained errors in $71,3 \%$ of the prescriptions. In 99,0\% of the prescriptions there were no complementary information and there was no signature from the pharmacist atesting to the dispensation in 99,8\% of them. It was concluded that none of the samples was in total conformity to the required specifications, what may compromise the pharmacotherapy and the patient's security, besides drive bacterial resistance.
\end{abstract}

Key words: Medication Errors; Prescriptions; AntiBacterial Agents; Safety patient.

\section{Resumo}

Entende-se como prescrição o documento de cunho legal elaborado por profissionais de saúde, sujeito à legislação de controle e vigilância sanitária. Constitui uma importante ferramenta de comunicação entre profissionais e o paciente, que em presença de irregularidades pode proporcionar o uso incorreto de medicamentos. $O$ objetivo deste estudo foi analisar erros de prescrição e dispensação de antimicrobianos em uma farmácia comunitária, de forma a verificar a frequência e fatores associados, de acordo com as legislações vigentes. Tratou-se de um estudo transversal, descritivo-analítico, executado a partir da análise documental de 404 prescrições de antimicrobianos tópicos e sistêmicos listados na $R D C n^{\circ} 20 / 2011$, disponibilizadas pela matriz de uma rede de farmácias, referentes ao mês de maio de 2018, utilizando um formulário préestabelecido elaborado com base no protocolo de segurança na prescrição, uso e administração de medicamentos. Os resultados demonstraram erros relacionados ao nome do paciente em $33,4 \%$, o carimbo do prescritor esteve ausente em $8,2 \%$ e o quesito de forma farmacêutica conteve erro em $71,3 \%$. Em 99,0\% das prescrições não havia informações complementares e não houve assinatura do farmacêutico atestando a dispensação em 99,8\%. Concluiu-se que nenhuma das amostras esteve em total conformidade aos requisitos exigidos, o que pode comprometer a farmacoterapia e segurança do paciente, além de impulsionar a resistência bacteriana.

Palavras chave: Erros de Medicação; Prescrições; Antimicrobianos; Segurança do Paciente. 


\section{Introdução}

Nas últimas décadas, as preocupações com a segurança do paciente se intensificaram no que concerne à gestão de riscos associados a medicações. Os medicamentos - embora sejam capazes de prevenir, diagnosticar e curar doenças ou aliviar sintomas -, estão permeados de riscos, devido aos diversos erros que podem ocorrer durante o curso do tratamento farmacológico ${ }^{1}$.

Dentre os mais importantes, os erros de medicação constituem um dos principais desafios, sendo responsáveis por 251 mil mortes ao ano nos Estados Unidos ${ }^{1}$. Esses erros representam um grave problema para os serviços de saúde, além de serem recorrentes em quase todas as instituições, em virtude da complexidade do processo terapêutico, com ocorrências durante a prescrição, dispensação ou administração de medicamentos, sendo os mais frequentes associados à prescrição ${ }^{1,2}$.

Entende-se como prescrição, o documento de cunho legal, elaborado por profissionais de saúde credenciados a estabelecer o medicamento necessário e apropriado, sujeito à legislação de controle e vigilância sanitária ${ }^{3}$. É uma importante ferramenta de transação entre prescritores e o paciente, pois se concebida de forma cuidadosamente elaborada, torna-se um elo de comunicação eficiente entre os profissionais envolvidos e o usuário. Por outro lado, não sendo de boa qualidade, a presença de irregularidades pode proporcionar dificuldades e erros na dispensação e administração, como também ocasionar uso incorreto de substâncias e resultar em eventos adversos evitáveis ${ }^{4,5}$.

Embora a prescrição seja o prelúdio para a terapêutica médica, com intrínseca responsabilidade quanto à restauração da saúde, com segurança, inúmeras falhas ainda são detectadas $^{5}$. Estima-se que mais de $50 \%$ dos medicamentos são prescritos, dispensados ou vendidos erroneamente, e que metade dos pacientes não os adquire adequadamente, sendo que nesse âmbito, os erros e a falta de informações das prescrições têm sido o foco de atenção para a causa ${ }^{6}$. Esses dados tornam-se ainda mais importantes ao serem relacionados com a utilização de antimicrobianos, cujo uso inadequado representa ameaça com gravidade crescente para a saúde pública7.

Os agentes antimicrobianos são fármacos que interrompem ou previnem o crescimento de microrganismos patogênicos no organismo, e estão entre os medicamentos mais comumente empregados em todo o mundo. A antibioticoterapia é composta por um conjunto de ações que visam otimizar a terapêutica, por meio da escolha mais apropriada, para cada tratamento em particular, da dose, via e tempo de administração específicos, para minimizar os efeitos indesejáveis, reduzir a toxicidade e evitar a resistência bacteriana ${ }^{8}$.

No Brasil, a venda de antibióticos é regulamentada desde 2010 e hoje é regida pela Resolução de Diretoria Colegiada (RDC) número 20 de 2011 da Agência Nacional de Vigilância Sanitária, Anvisa9 ${ }^{9}$. No entanto, o fenômeno de resistência é uma ameaça constatada para a saúde global e um dos desafios estabelecidos pela Organização Mundial de Saúde ${ }^{10}$. Estima-se que esta seja a causa da morte de aproximadamente 700.000 pessoas por ano, e que em 2050, se o cenário atual perpetuar, esse número aumente para 10 milhões e cumule gasto de 100 trilhões de dólares em atendimentos ${ }^{11,122}$.

Considerando que a prescrição inadequada de medicamentos é apontada como um problema de saúde pública, que interfere na qualidade da dispensação, diminui a segurança do paciente e eleva o risco de reações adversas, morbidade, mortalidade e resistência ${ }^{12}$, estudos sobre o tema possibilitam identificar falhas, e, consequentemente, inferir os possíveis fatores associados. Adicionalmente, a investigação dos erros nas prescrições de antimicrobianos é útil para associação aos dados de resistência bacteriana, e vale como base para criação de intervenções voltadas à conscientização de prescritores.

Assim, o estudo teve como objetivo analisar erros de prescrição e dispensação de antimicrobianos em uma farmácia comunitária, de forma a verificar a frequência e fatores associados.

\section{Metodologia}

\section{Tipo e local de estudo}

Estudo de caráter transversal, executado a partir da análise documental de 404 prescrições de antimicrobianos tópicos e sistêmicos listados na RDC $n^{\circ} 20 / 2011^{9}$, disponibilizadas pela Matriz de uma rede de Farmácias localizada em uma cidade do Sudoeste da Bahia que é referência para 26 municípios da Base Regional de Saúde Sul. 
Amostra, processo de amostragem e critérios de inclusão e exclusão

A amostra desse trabalho foi composta por prescrições disponibilizadas pela referida Farmácia. A segunda via da receita, depois da dispensação do medicamento, se torna documento pertencente ao estabelecimento farmacêutico, o qual deve prestar as informações ou realizar a entrega de documentos dentro dos prazos determinados para manter-se em regularidade com a vigilância sanitária, conforme a RDC 20 de $2011^{9}$. Essas vias são utilizadas também para a escrituração semanal que é enviada à Anvisa pela farmácia através do Sistema Nacional de Gerenciamento de Produtos Controlados (SNGPC). Devem ser arquivadas durante dois anos, para atender a quaisquer inspeções sanitárias, e incineradas após o tempo ${ }^{13}$

No cálculo da amostra, realizado com auxílio da ferramenta StatCalc do software Epinfo, versão 7.0, considerou-se um erro alfa de $5 \%$, erro beta de $10 \%$, tendo como referência a prevalência de erros de prescrição de um trabalho realizado em hospital brasileiro $(292,5$ erros por 1000 itens $)^{14}$, resultando em 303 prescrições. No entanto, durante a realização da coleta, optou-se por finalizar o mês de Maio, período em que a coleta de dados foi efetuada, o que totalizou 404 prescrições.

Foram considerados como critério de inclusão prescrições que contiveram ao menos um antimicrobiano de uso tópico ou sistêmico, aviadas e retidas pela Farmácia em período anterior à coleta, e foram excluídas aquelas que contiveram antimicrobianos que não constam na RDC 20 de 2011. O mês de execução da coleta de dados foi definido através de sorteio entre os doze meses do ano de 2018.

\section{Coleta de dados, instrumento e variáveis}

Os dados foram colhidos das receitas retidas no mês de maio do ano de 2018, e compilados em um formulário de avaliação da prescrição, composto por cinco blocos de conteúdo, elaborado com base no Protocolo de Segurança na Prescrição, Uso e Administração de Medicamentos ${ }^{15}$, como parte do Programa Nacional de Segurança do Paciente (PNSP), Anvisa e Ministério da Saúde (MS). Para o preenchimento do formulário, foi considerada "Correta" a descrição apresentada de maneira completa e legível, e "Errada" em caso de ausência, incompletude ou ilegibilidade dos dados obrigatórios da prescrição de antimicrobianos.

As variáveis dependentes foram: relativas ao paciente - nome, endereço, idade, sexo e peso; ao medicamento: nome do fármaco escrito sob forma de Denominação Comum Brasileira (DCB) ou pelo nome comercial, concentração, forma farmacêutica, via de administração, frequência de administração, dose e duração do tratamento; ao prescritor - nome, carimbo, assinatura, número de inscrição no Conselho Regional, especialidade; endereço e telefone da instituição; à dispensação: quantidade aviada, número do lote do medicamento dispensado, número de identidade do paciente e assinatura do farmacêutico; e informações complementares data, orientação de uso, orientação de armazenamento, forma de elaboração manuscrita, digitada (realizada no computador e impressa, contendo apenas a assinatura em manuscrito) ou mista (mescla de parte impressa e escrita à mão); uso de abreviaturas, uso de expressões vagas, origem de estabelecimento público ou privado e prescrição concomitante a outros medicamentos.

Considerou-se como variáveis independentes o tipo de prescritor (médico, dentista ou veterinário), a forma de elaboração da prescrição (manuscrita, digitada ou mista) e a origem (pública ou privada).

As variáveis dependentes (erro de prescrição e de dispensação) foram classificadas e avaliadas de acordo com a definição do Protocolo de Segurança na Prescrição, Uso e Administração de Medicamentos ${ }^{15}$. Conforme esse documento, considera-se como erro de prescrição aquele que "ocorre durante a prescrição de um medicamento, em decorrência tanto de redação da prescrição, como do processo de decisão terapêutica [...]", e julga-se erro de dispensação o "desvio na interpretação da prescrição, cometido pela equipe da farmácia quando da realização da dispensação, [...] incluem também erros relacionados às normas $\mathrm{e}$ à legislação".

\section{Análise dos dados}

Para tabulação, foi utilizado o Software EpiData, na sua versão licenciada 3.1, e a análise estatística realizada no Software Statistical Package for the Social Sciences - SPSS, versão 21.0. Foram realizadas distribuição de frequência absoluta e relativa, além do teste de quiquadrado para avaliar a associação entre a variável dependente e as explicativas, considerando $p<0,05$. Para avaliação da normalidade de variáveis contínuas realizou-se o 
teste de Kolmogoroy-Smirnov, considerando $p>0,05$

\section{Resultados e Discussões}

A partir da análise de 404 prescrições, foi possível obter informações sobre erros nos dados de identificação de pacientes, medicamentos, prescritores, uso concomitante de antimicrobianos a outros medicamentos, informações complementares e sobre a dispensação.

Do total verificado, 264 (65,3\%) apresentaram-se na forma manuscrita, 128 (31,7\%) na forma digitada e $12(3,0 \%)$ na forma mista; em $24,8 \%$ a data não estava presente. No que se refere aos dados sobre o paciente $33,4 \%$ das informações relativas ao nome continham erros e $99,5 \%$ do endereço e peso estavam ausentes ou com incompletude no preenchimento.

Em 315 das prescrições foi verificado algum erro nos dados sobre prescritor, sendo que a omissão do carimbo $(8,2 \%)$ foi um dos itens que obteve maior expressividade. Verificou-se também que a maioria dos receituários $(92,1 \%)$ foi elaborada por profissionais médicos, enquanto $5,7 \%$ dos prescritores foram dentistas e 2,2\% médicos veterinários. A Tabela 1 mostra a distribuição dos erros relativos à ausência de informações sobre o paciente, prescritor e instituição.

Tabela 1. Frequência de erros de prescrição referentes à identificação da instituição, paciente e prescritor em prescrições ambulatoriais de antimicrobianos, conforme o processo de elaboração da prescrição. Bahia, Brasil, 2018.

\begin{tabular}{ccccc}
\hline & \multicolumn{4}{c}{ Erros $\mathbf{n}(\%)$} \\
& Manuscrita & Digitada & Mista & * -valor \\
\cline { 2 - 5 } Instituição & & & & \\
Endereço & $78(29,5)$ & $2(1,6)$ & $0(0,0)$ & $<0,001$ \\
Telefone & $81(30,7)$ & $47(36,7)$ & $0(0,0)$ & 0,005 \\
& & & & \\
Paciente & & & & \\
Endereço & $264(100)$ & $126(98,4)$ & $12(100)$ & 0,115 \\
Peso & $263(99,6)$ & $127(99,2)$ & $12(100)$ & 0,611 \\
& & & & \\
Prescritor & & & & \\
Nome & $17(6,4)$ & $5(3,9)$ & $1(8,3)$ & 0,551 \\
Carimbo & $22(8,3)$ & $9(7,0)$ & $2(16,7)$ & 0,500 \\
Assinatura & $2(0,8)$ & $1(0,8)$ & $0(0,0)$ & 0,913 \\
Total & $24(9,1)$ & $3(2,3)$ & $1(8,3)$ & 0,047 \\
\hline
\end{tabular}

Fonte: Elaboração dos autores.

Identificou-se 143 prescrições $(35,4 \%)$ provenientes do Sistema Público de Saúde. Destas, 62,9\% foram manuscrita, 35,7\% digitadas e $1,4 \%$ mistas. Do setor privado foram 261 prescrições $(64,6 \%)$, sendo $66,7 \%$ em elaboração manuscrita, $29,5 \%$ digitadas e $3,8 \%$ mistas.

Do total, a maioria dos medicamentos $(53,5 \%)$ foi prescrita sob a denominação comercial, enquanto $45,2 \%$ apareceram com o nome genérico (Denominação Comum Brasileira). Já relacionando a origem com o tipo de denominação, das prescrições de setor público, $62,2 \%$ exibiram nome genérico, e $37,8 \%$ designação comercial. Por outro lado, no setor privado, esses resultados foram de $36,8 \%$ e $63,2 \%$, respectivamente.

Dos elementos analisados sobre as informações do medicamento, apresentados na Tabela 2, o quesito que apresentou maior quantidade geral de erros foi o de forma farmacêutica (71,3\%). Apenas o nome do medicamento obteve presença positiva mais expressiva, sem erros em $96,8 \%$ dos documentos.

Dentre as 404 prescrições, 54,0\% continham mais de um medicamento prescrito. Ao todo, foram prescritos 755 medicamentos, gerando mediana 2,0 e intervalo interquartil 1,0 . No Gráfico 1 , com relação à distribuição das classes dos antimicrobianos, a maior parte $(34,1 \%)$ foi pertencente à classe de $\beta$-lactâmicos, seguidos dos macrolídeos $(25,2 \%)$. Os fármacos que mais apareceram foram a amoxicilina e a azitromicina.

Além dessas, outras classes de medicamentos foram prescritas para uso concomitante aos antimicrobianos, sobressaindo os antiinflamatórios não esteroides $(24,1 \%)$ e os analgésicos (18,1\%). 
Tabela 2. Frequência de erros de prescrição referentes aos dados dos medicamentos antimicrobianos em prescrições ambulatoriais. Bahia, Brasil, 2018.

\begin{tabular}{|c|c|c|c|c|c|c|c|c|c|}
\hline \multicolumn{10}{|c|}{ Erros n (\%) } \\
\hline & Nome & DCB & Concentração & FF & Via de Adm. & Frequência & Dose & Duração & Total \\
\hline \multicolumn{10}{|c|}{ Tipo de prescrição } \\
\hline Manuscrita & $10(3,8)$ & $144(54,5)$ & $117(44,3)$ & $211(79,9)$ & $205(77,7)$ & $57(21,6)$ & $166(62,9)$ & $127(48,1)$ & $N=1.037$ \\
\hline Digitada & $3(2,3)$ & $67(52,3)$ & $40(31,3)$ & $74(57,8)$ & $59(46,1)$ & $8(6,3)$ & $57(44,5)$ & $19(14,8)$ & $N=327$ \\
\hline Mista & $0(0,0)$ & $8(66,7)$ & $7(58,3)$ & $3(25,0)$ & $4(33,3)$ & $0(0,0)$ & $1(8,3)$ & $8(66,7)$ & $N=31$ \\
\hline$*_{p}$-valor & 0,499 & 0,624 & 0,021 & $<0,001$ & $<0,001$ & $<0,001$ & $<0,001$ & $<0,001$ & - \\
\hline \multicolumn{10}{|l|}{ Prescritor } \\
\hline Médico & $13(3,5)$ & $213(57,3)$ & $158(42,5)$ & $267(71,8)$ & $249(66,9)$ & $60(16,1)$ & $207(55,6)$ & $146(39,2)$ & $\mathrm{N}=1.313$ \\
\hline Dentista & $0(0,0)$ & $2(8,7)$ & $2(8,7)$ & $16(69,6)$ & $13(56,5)$ & $4(17,4)$ & $14(60,9)$ & $6(26,1)$ & $N=57$ \\
\hline Veterinário & $0(0,0)$ & $4(44,4)$ & $4(44,4)$ & $5(55,6)$ & $6(66,7)$ & $1(11,1)$ & $3(33,3)$ & $2(22,2)$ & $N=25$ \\
\hline${ }^{*}$ p-valor & 0,336 & $<0,001$ & 0,006 & 0,863 & 0,591 & 0,907 & 0,357 & 0,276 & - \\
\hline \multicolumn{10}{|l|}{ Origem } \\
\hline Pública & $8(5,6)$ & $54(37,8)$ & $48(33,6)$ & $111(77,6)$ & $97(67,8)$ & $13(9,1)$ & $80(55,9)$ & $42(29,4)$ & $\mathrm{N}=453$ \\
\hline Privada & $5(1,9)$ & $165(63,2)$ & $116(44,4)$ & $177(67,8)$ & $171(65,5)$ & $52(19,9)$ & $144(55,2)$ & $112(42,9)$ & $\mathrm{N}=942$ \\
\hline$* \mathrm{p}$-valor & 0,045 & $<0,001$ & 0,033 & 0,097 & 0,638 & 0,005 & 0,881 & 0,007 & - \\
\hline Total & $\mathrm{N}=39$ & $\mathrm{~N}=657$ & $\mathrm{~N}=492$ & $\mathrm{~N}=864$ & $\mathrm{~N}=804$ & $\mathrm{~N}=195$ & $\mathrm{~N}=672$ & $\mathrm{~N}=462$ & $\mathrm{~N}=4.185$ \\
\hline
\end{tabular}


O uso de expressões vagas apareceu em apenas $1,0 \%$ das prescrições. De modo similar, em 99,0\% dos receituários, não foram identificadas informações complementares, como relativas a formas específicas de uso, horários para administração ou possíveis interações com outros medicamentos e/ou alimentos; e em 99,8\% não houve menção sobre condições ideais de armazenamento.

Gráfico 1. Classificação ATC de antimicrobianos de prescrições ambulatoriais. Bahia, Brasil, 2018.

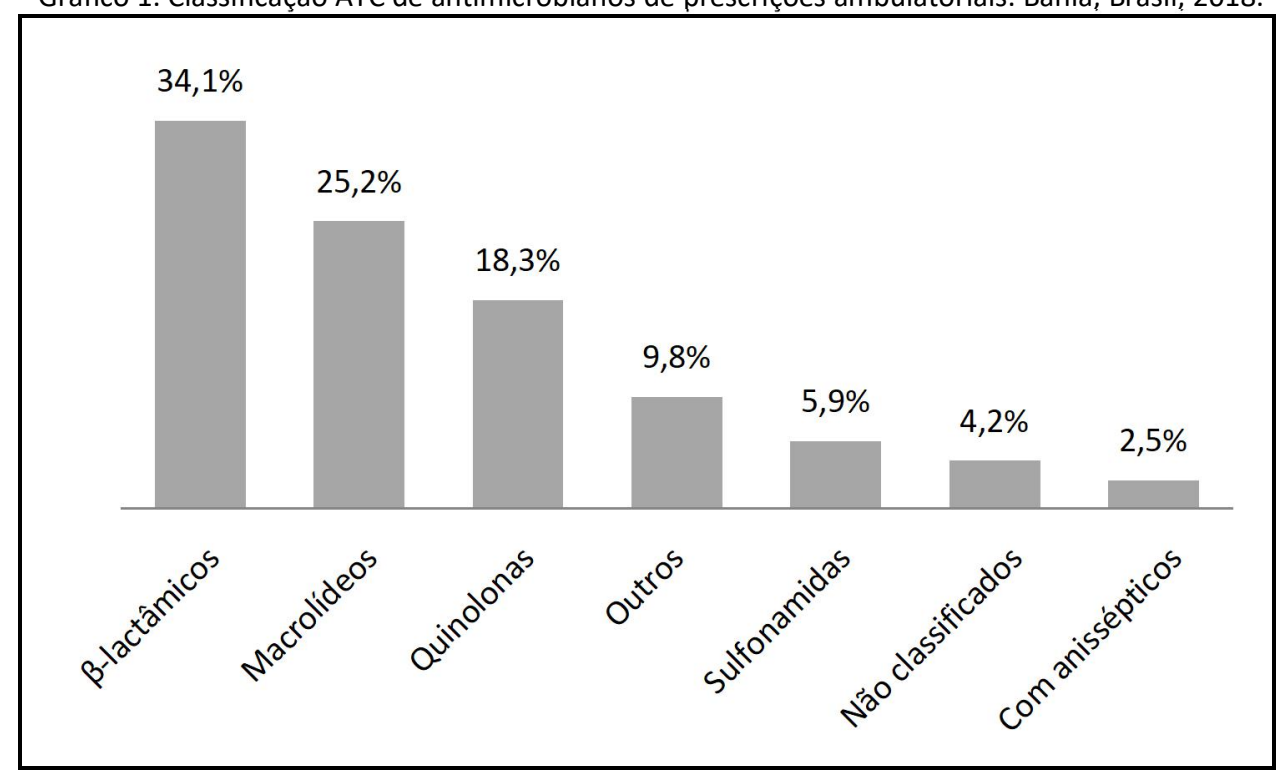

Fonte: Elaboração dos autores.

Conforme a Tabela 3 , no relativo à dispensação, 99,8\% das receitas aviadas não continham assinatura do farmacêutico, e outras irregularidades, como a retenção de $1 \underline{\text { a }}$ via da prescrição em lugar da $2 \underline{a}$ via $(80,4 \%)$ também foram demonstradas.

Tabela 3. Frequência de erros relativos à dispensação de medicamentos antimicrobianos. Bahia, Brasil, 2018.

\begin{tabular}{ccr}
\hline Variáveis & \multicolumn{2}{c}{ Erros } \\
\hline & $\mathbf{n}$ & $\%$ \\
\cline { 2 - 3 } № de identidade do paciente & 403 & 99,8 \\
Quantidade aviada & 32 & 7,9 \\
Número do lote & 54 & 13,4 \\
Assinatura do farmacêutico & 403 & 99,8 \\
Data da dispensação & 23 & 5,7 \\
\hline Total & $\mathrm{N}=837$ \\
\hline Fonte: Elaboração dos autores.
\end{tabular}

Compreender como os medicamentos são prescritos é útil para promover melhorias no processo de prescrição, dispensação e uso de medicamentos. Os resultados obtidos nos itens avaliados nesta pesquisa mostram uma desconformidade de preenchimento de dados na prescrição e dispensação dos medicamentos, expressando a falta de concordância dos profissionais em referência às legislações vigentes, o que pode comprometer a comunicação entre os envolvidos e afetar a qualidade da assistência farmacêutica e o resultado clínico do paciente ${ }^{13}$.

A maior parte das prescrições foi elaborada de forma manuscrita, demonstrando resultado semelhante a um estudo ${ }^{16}$ realizado em farmácia comercial do município de Imperatriz-MA, em que estas foram correspondentes a 90,8\%. A baixa legibilidade desse documento, especialmente quando elaborado a punho, tem sido relacionada como uma considerável causa de falha na interlocução entre os profissionais na assistência ao paciente e fator colaborador para erros de medicação, podendo resultar em diversos problemas, entre eles o desenvolvimento de interpretações equivocadas $^{16-18}$.

A ausência da data nas prescrições de antimicrobianos foi menor em comparação a um estudo $^{18}$ realizado a partir da análise documental de prescrições de antimicrobianos retidas em uma Farmácia Básica, em que a inexistência foi de 33,3\%. Essa informação é indispensável para garantir a validade da receita médica, além de ser um referencial para o acompanhamento da evolução histórica do paciente e para que este possa ser avaliado a cada período de tempo padronizado ${ }^{19-20}$. Além disso, a inexistência da data impede o dispensador de conhecer a validade da prescrição, acarretando danos à orientação farmacêutica. Outrossim, o não 
preenchimento desse campo pode proporcionar a ocorrência de fraudes e viabilizar o uso irracional dos medicamentos, pois ficará a cargo do paciente decidir a data da compra e do uso das substâncias prescritas ${ }^{13}$.

A prescrição de medicamentos é um documento de cunho pessoal e intransferível, e por isso precisa incluir informações específicas sobre o usuário para a qual foi emitida. Assim, a falta da identificação pode ser um empecilho para o contato do farmacêutico após a dispensação, caso seja necessário ${ }^{21}$. No entanto, uma quantidade significativa das receitas avaliadas nesse estudo apresentou falha em algum dos campos relativos aos dados do paciente, especialmente em prescrições manuscritas, como a falta ou incompletude do nome, discordante ao resultado encontrado em trabalho realizado em uma unidade básica de saúde ${ }^{22}$.

Considerando que a prescrição é individualizada, ela deve ser aviada apenas quando portar nome e endereço do paciente, a fim de poupar e expor a riscos evitáveis. Também, a idade e o peso são outros pontos importantes, de forma especial quando se trata de populações pediátricas e geriátricas, para que possa ser verificada a adequação da dose ${ }^{23}$. Chama-se atenção ainda ao fato de que a RDC 20/2011 descreve uma lista com 119 substâncias antimicrobianas que necessitam ser lançadas eletronicamente, via internet, através do Sistema Nacional de Gerenciamento de Produtos Controlados (SNGPC), onde é realizado o registro da movimentação de entradas e saídas dessas substâncias. Nesse sistema são exigidos elementos sobre o paciente, salientando a importância desses dados ${ }^{23}$.

Quanto aos dados de identificação do prescritor, como nome, assinatura, endereço e telefone da instituição e sua inscrição no conselho profissional, são úteis principalmente para viabilizar a identificação, localização e contato em ocorrência de dúvidas durante a dispensação ou administração do medicamento prescrito $^{5,13}$. Na pesquisa, campos de maior ausência nesse âmbito foram os de carimbo e assinatura, semelhante a estudo ${ }^{24}$ em outra drogaria privada, no qual se ressaltou a ausência desses em 75,5\% das receitas. Esses itens funcionam como uma ferramenta técnica e prática para comunicação com o remetente, e também conferem validade legal à prescrição, de forma que em casos de ausência ou ilegibilidade dessas informações, os fármacos não devem ser dispensados. Adicionalmente, também contribuem para evitar fraudes e adulterações ${ }^{13}$.
No que diz respeito à $D C B$ existe uma obrigatoriedade de adesão, regida por portaria e lei brasileira, no âmbito do Sistema Público de Saúde, sendo facultativa aos Serviços Privados de Saúde, em que os fármacos podem ser prescritos em denominação genérica ou comercial ${ }^{25}$. No presente trabalho, na análise geral quase metade das prescrições avaliadas contiveram substâncias prescritas em nome genérico, sendo que a não adesão à DCB esteve associada a prescrições de origem privada. Das prescrições provenientes do setor público, 62,2\% estavam de acordo à $D C B$, de forma diferente do estudo ${ }^{18}$ desenvolvido numa Farmácia Escola, em que apenas 1,82\% não contiveram esse tipo de denominação.

A não adesão pelo nome genérico pode ser influenciada pela ampla variedade de apresentações comerciais com o mesmo princípio ativo, pela confiabilidade do prescritor em laboratórios farmacêuticos específicos ${ }^{26}$, por alguns antimicrobianos não estarem descritos na Relação Nacional de Medicamentos Essenciais (RENAME) (e que por isso não podem ser disponibilizados de forma gratuita) $)^{23-24}$, ou por falha na divulgação e conscientização pela adoção da DCB e seu coexistente comprometimento com o acesso aos medicamentos, visto que facilita ao paciente a chance de intercambialidade ${ }^{25}$. Porém 0 baixo custo e a qualidade comprovada dos medicamentos genéricos são uma importante ferramenta de contribuição à adesão do tratamento, permitindo que a população geral tenha acesso a produtos farmacêuticos de qualidade com valor acessível, ressaltando a necessidade de conscientização e adequação às legislações pelos profissionais da saúde $\mathrm{e}^{13,24}$.

Por sua vez, as informações sobre o medicamento possuem um aspecto relevante a ser considerado nas receitas médicas, pois o tratamento estabelecido visa alcançar uma determinada meta farmacoterapêutica, e a falta de elementos neste campo, como, por exemplo, a inexistência da dose, pode gerar uma terapia inadequada e acarretar em frustração aos objetivos, por parte do prescritor e do paciente ${ }^{20,27}$. Mesmo assim, a pesquisa demonstrou números de erros significativos em elementos como via de administração (66,3\%), forma farmacêutica $(71,3 \%)$, de forma maior do que em outro estudo ${ }^{18}$ executado em Farmácia Escola.

Falhas relacionadas à via de administração podem resultar em administração por vias e/ou técnica de aplicação inadequadas, causando alteração dos fatores farmacocinéticos do fármaco, sobretudo em relação à absorção, 
aumentando o risco de reações adversas ${ }^{20}$. De igual modo, a forma farmacêutica apresentada da maneira correta é imprescindível, considerando que determinadas substâncias possuem diferentes apresentações para administração oral, tópica ou parenteral, oportunizando erros durante a dispensação e administração ${ }^{26}$.

A frequência de administração, que esteve ausente em 15,9\% das prescrições, é uma variável necessária para o uso correto dos medicamentos, tendo em vista que intervalos maiores do que o necessário entre as doses podem reduzir o efeito e comprometer o resultado esperado; e, por outro lado, intervalos menores do que o correto podem ser causadores de intoxicação e reações adversas. De forma complementar, a duração do tratamento evita que os fármacos sejam consumidos continuamente, diminuindo as chances de ocorrerem interações medicamentosas e/ou intoxicações ${ }^{6}$.

Os erros de prescrição relacionados à identificação do paciente e do prescritor, bem como as informações sobre o medicamento, estiveram associados em maior parte a prescrições manuscritas. Nesse sentido, a implantação do sistema de prescrição eletrônica tem sido apontada como estratégia para diminuição dos erros de medicação. No cenário nacional e internacional, as investigações comparativas entre prescrições manuais e eletrônicas demonstraram diminuição nas taxas de erros de prescrição, assim como maior melhoria dos pacientes ${ }^{4,27-29}$. Apesar das vantagens, o alto custo do sistema e o risco da implementação ser ineficaz, podendo gerar consequências indesejadas, são fatores a serem considerados $^{29}$.

Dos antimicrobianos, a maior parcela foi a dos $\beta$-lactâmicos, assim como em outro trabalho ${ }^{24}$ em que estes foram dispensados em drogaria. A segunda classe mais prescrita foi a dos macrolídeos, com resultado superior a outra pesquisa ${ }^{24,26}$ realizada com antimicrobianos dispensados em farmácia privada. Considerando as substâncias, a amoxicilina, assim como em outros $\operatorname{casos}^{19,24,30}$ foi a mais prevalente, todavia ela tem sido apontada como o grupo que mais contribui para a resistência bacteriana, e que estão sendo prescritos abusivamente ${ }^{30}$.

Em relação à observação dos medicamentos prescritos juntamente com os antimicrobianos, assim como em outra pesquisa ${ }^{23}$, foi revelado o uso frequente de antiinflamatórios não esteroides (AINEs) e analgésicos. Entretanto, caso haja utilização de forma incorreta, com superdosagem ou tempo prolongado, pode representar perigo à saúde dos usuários, pois é capaz de haver interações medicamentosas que causem efeitos como irritação na mucosa gastrointestinal inferior, lesão hepática, indução de neutropenia, inibição plaquetária, reações de hipersensibilidade, além de efeitos pulmonares, na pressão arterial, no sistema nervoso central e nas cartilagens ${ }^{22}$.

No que se refere às orientações complementares, apesar de sua relevância em registrar, para o paciente, conhecimentos importantes que foram ditos verbalmente (ou não), e que podem repercutir na qualidade do tratamento e da dispensação, não foram constatadas em nenhuma das receitas averiguadas. Atrelado a isso, há uma preocupação com relação ao esquema terapêutico definido, uma vez que o paciente deixa a farmácia portando o produto adquirido e instruções verbais mencionadas pelo médico durante a consulta, ou pelo farmacêutico durante a dispensação, e que podem facilmente ser esquecidas. Assim, é apropriado que o usuário permaneça com uma via da prescrição, contendo as informações complementares, através da qual possa manter-se seguro sobre o tratamento ${ }^{23-24}$.

No momento da dispensação, faz-se necessária conferência de todos os componentes obrigatórios da prescrição, que são de fundamental importância para a execução da terapêutica, precaução de erros e eventos adversos, promoção do uso adequado e legalidade dos dados ${ }^{19,23-24}$. Ademais, de acordo com a RDC $20 / 2011^{9}$, também há campos que são de incumbência do farmacêutico preencher nessa etapa. Na via da prescrição retida na farmácia, deve conter o nome completo, número do documento de identificação e endereço do comprador; além da quantidade e número do lote do medicamento dispensado e data em que ocorreu.

A identificação do comprador auxilia no controle de erros e fraudes, a data da dispensação comprova que a receita foi aviada dentro do prazo de validade legal e a anotação do número do lote do medicamento e quantidade aviada são obrigatórios para o registro do mesmo e controle de estoque realizados no SNGPC ${ }^{15,24}$. Embora tudo isso deva estar apontado na 2a via da prescrição, chama-se atenção à ausência dessa via em mais da metade dos casos, permanecendo a farmácia com a receita original (1 $1 \underline{a}$ via), que deve ficar em posse do paciente.

Percebe-se que avaliar erros nas prescrições 
é também examinar a qualidade de uma parcela dos serviços de saúde prestados. É necessário enxergar esse documento como de caráter terapêutico, para que seja um material efetivo na garantia do uso racional de medicamentos e da adesão ao tratamento, prevenindo uso ilícito e eventos adversos, diminuindo gastos evitáveis em saúde. Para tanto, a presença do profissional farmacêutico e o preenchimento adequado das receitas são importantes para prevenir erros e proporcionar um tratamento eficaz e seguro ${ }^{19-}$ 200,23-24.

Ressalta-se que o presente trabalho apresenta limitações, pois apesar da relevância dos resultados obtidos, trata-se de uma farmácia comunitária, a partir da qual foram coletados dados de um único período de tempo, não podendo generalizar a outras organizações e circunstâncias. Porém, os resultados expressam a necessidade desse tipo de avaliação, e podem contribuir para a criação de projetos de capacitação e melhoramento no processo de prescrição e dispensação de medicamentos.

\section{Conclusão}

Esse estudo expôs importantes erros de prescrição e dispensação em prescrições de antimicrobianos, com relação ao preconizado pelas legislações vigentes, evidenciando que nenhuma das amostras esteve em total conformidade aos requisitos exigidos e que muitos dos erros estiveram associados a receitas de elaboração manuscrita. Esse cenário obstaculiza pleno sucesso farmacoterapêutico, contribui para a falta de adesão aos tratamentos, compromete a qualidade da dispensação e expõe o paciente a diferentes tipos de riscos tocantes a administração e utilização de medicamentos, além de impulsionar a resistência bacteriana.

Assim, constata-se a necessidade de conscientização e atualização dos profissionais, salientando a relevância em tratar a prescrição como documento terapêutico, base da farmacoterapia, de forma que prescritores e dispensadores mantenham-se cientes de suas responsabilidades e comprometimentos com os aspectos legais e sanitários, tal como com a segurança do paciente. Evidencia-se também o papel do farmacêutico como substancial à adequada avaliação da prescrição e dispensação de boa qualidade, que proporcionam benefícios para melhoria da situação atual.

\section{Referências}

1. Pires AOM, Ferreira MBG, Nascimento KG, Felix MMS, Pires OS, Barbosa MH. Elaboração e validação de Lista de Verificação de Segurança na Prescrição de Medicamentos. Rev Latino-Am Enfermagem. 2017;25(3):21-29.

2. Albarrak Al, Al Rashidi EA, Fatani RK, Al Ageel SI, Mohammed R. Assessment of legibility and completeness of handwritten and electronic prescriptions. Saudi Pharm Journal. 2014;22(6):522-527.

3. Brasil. Ministério da Saúde. Portaria n. 3.916, de 30 de outubro de 1998. Aprova a Política Nacional de Medicamentos. Disponível em:

http://bvsms.saude.gov.br/bvs/saudelegis/gm/1 998/prt3916_30_10_1998.html

4. Santana RS, Lucas dos Santos Silva, Cruz IMA, Lemos GS, Perini E, Lopes CRS. SECH: sof software de gerenciamento farmacêutico e prescrição eletrônica. Rev. Saúde.Com. 2016;12(4):680-687.

5. Silva JSD, Almeida PHRF, Perini E, Padua CAM, Rosa MB, Lemos GS. Erros de prescrição e administração envolvendo um medicamento potencialmente perigoso. Revista de enfermagem UFPE. 2017;11(10):3707-3717.

6. Riaz

K, Hashmi FK, Bukhari NI, Riaz M, Hussain K. Occurrence of medication errors and comparison of manual and computerized prescription systems in public sector hospitals in Lahore, Pakistan. PloS one. 2014;9(8).

7. Ncube NBQ, Solanki GC, Kredo T, Lalloo R. Antibiotic prescription patterns of South African general medical practitioners for treatment of acute bronchitis. South African Medical Journal. 2017;107(2):119-122.

8. Pereira JQ, Silva MT, Galvão TF. Use of antibiotics by adults: a population-based crosssectional study. Sao Paulo Medical Journal. 2018;136(5):407-413.

9. Brasil. Ministério da Saúde. Resolução RDC n. 20, de 5 de maio de 2011. Dispõe sobre o controle de medicamentos à base de substâncias classificadas como antimicrobianos, de uso sob prescrição, isoladas ou em associação. Disponível em:

http://bvsms.saude.gov.br/bvs/saudelegis/anvisa 2011/rdc0020 0505 2011.html

10. Organização Mundial da Saúde. Dez ameaças à saúde que a OMS combaterá em 2019. Brasília, DF: OMS; 2019.

11. Farley E, Stewart A, Davies MA. Antibiotic use and resistance: Knowledge, attitudes and perceptions among primary care 
prescribers in South Africa. South African Medical Journal. 2018;108(9):763-771.

12. Rivera PL. Prescripción inadecuada de fármacos y su relación con el cumplimiento terapéutico en pacientes polimedicados. Gerokomos. 2018;29(3):123-127.

13. Souza SSS, Pinheiro MTRS, Almeida PHRF, Lemos LB, Lemos GS. Sibutramina: falhas e incompletude de documentos na prescrição e dispensação. Revista de Atenção à Saúde. 2017; 15(51):23-33.

14. Neri EDR, Gadelha PGC, Maia SG, Pereira AGS, Almeida PC, Rodrigues CRM, et al. Erros de prescrição de medicamentos em um hospital Brasileiro. Revista Associação Médica Brasileira. 2011;57(3):306-316.

15. Brasil. Ministério da Saúde. Agência Nacional de Vigilância Sanitária. Protocolo de segurança na prescrição, uso e administração de medicamentos do programa nacional de segurança do paciente [Internet]. 2013 [citado em 23 Jan 2019]. Disponível em: https://www20.anvisa.gov.br/segurancadopacie nte/index.php/publicacoes/item/seguranca-na-

prescricao-uso-e-administracao-demedicamentos.

16. Martins NB, Souza LMG, Torres MLD, Firmo WCA. Análise da prescrição médica de antibióticos de uma farmácia comercial no município de Imperatriz-MA. Rev Cien ITPAC. 2014;7(4).

17. Oliveira CS, Santos AS, Leite ICG. Avaliação da qualidade das prescrições médicas da farmácia municipal de Catalão - Goiás. Rev Med de Min Ger. 2015;25(4).

18. Souza SF, Maynardes NM, Xavier MP. Análise do perfil das prescrições médicas e da dispensação farmacêutica em uma farmácia escola do municipío de Gurupi-TO. Amaz Sci Heal. 2014;2(1).

19. Lucena NP, Araújo VR, Araújo LLN. Levantamento das prescrições de antimicrobianos dispensadas na farmácia básica, no município de Niquelândia-GO. Rev eletr de cien hum saú e tec. 2015;4(1).

20. Guzatto P, Bueno D. Análise de prescrições medicamentosas dispensadas na farmácia de uma unidade básica de saúde de Porto Alegre - RS. Rev HCPA. 2007;27(3):20-26.

21. Zanetti MOB, Marchetti JM, Andrade RCG. Adequação da prescrição de medicamentos na atenção primária à saúde de Ribeirão Preto-SP: estudo transversal. Rev bras de med da fam e comum. 2017;12(39).

22. Bandeira VAC, Herrman CTS, Siqueira CM, Oliveira KR. Análise das prescrições dispensadas em uma unidade básica de saúde do município de ljuí - RS. Rev saúde (Santa Maria). 2015;41(1).

23. Alves CDS, Santos RG, Lemos GS. Análise da completude das prescrições médicas de antimicrobianos dispensadas em farmácia comunitária de Jequié, Bahia. Rev baiana saúd púb. 2017;41(11).

24. Polisel CG, Bergê RS. Avaliação da conformidade de prescrições médicas e dispensação de antimicrobianos. Revista Brasileira em Promoção da Saúde. 2014;27(1):2128.

25. Brasil. Ministério da Saúde. Lei n. 9.787, de 10 de fevereiro de 1999. Estabelece o medicamento genérico, dispõe sobre a utilização de nomes genéricos em produtos farmacêuticos e dá outras providências. Disponível em: http://www.planalto.gov.br/ccivil_03/LEIS/L9787. htm

26. Ferreira TA, Ferreira FD. Qualidade da prescrição de antimicrobianos comercializados na região noroeste do Paraná, Brasil. SaBios rev de saúde e biol. 2015;10(1).

27. Murta IAA, Bastos CB, Lacerda LV, Rocha ED, Gomes IL, França DS. Análise da qualidade das prescrições médicas em Montes ClarosMinas Gerais. Revista Eletrônica Acervo Saúde, 2019;11(7):e615.

28. Nuckols TK, Smith-Spangler C, Morton SC, Asch SM, Patel VM, Anderson LJ, et al. The effectiveness of computerized order entry at reducing preventable adverse drug events and medication errors in hospital settings: a systematic review and meta-analysis. Syst Rev. 2014;3(56).

29. Volpe CRG, Melo EMM, Aguiar LB, Pinho DLM, Stival MM. Fatores de risco para erros de medicação na prescrição eletrônica e manual. ver. Latino-Am. Enfermagem. 2016;24:e2742.

30. Nogueira AG, Moraes EV, Toledo OR, Oliveira CC, David FL. Falhas na prescrição e dispensação de antimicrobianos em uma farmácia básica na amazônia legal, Brasil. Rev da Univ Vale do Rio Verde. 2015;13(1).

\section{Endereço para Correspondência}

Estr. Bem Querer, Km-04 - 3293, 3391 - Campus de, Vitória da Conquista - BA

CEP.: 45083-900

e-mail: giselesilveiralemos@gmail.com

Recebido em 03/09/2019

Aprovado em 12/12/2019

Publicado em 13/02/2020 